\title{
Lakes and ponds as model systems to study parallel evolution
}

\author{
Juha MERILÄ* \\ Ecological Genetics Research Unit, Department of Biosciences, PO Box 65, FI-00014 University of Helsinki, Finland \\ *Corresponding author: juha.merila@helsinki.fi
}

\begin{abstract}
Population genetic theory predicts that effective population size and gene flow can strongly influence the levels and patterns of genetic variability, and thereby also the likelihood, pace and direction of evolutionary transformations. Given that levels and patterns of genetic variability in lakes and ponds often differ from those observed in continuous marine environments, it follows that the dynamics of adaptation and evolution in freshwater habitats are also likely to differ from those in marine habitats. Here, I explore and discuss some ideas relating to the likelihood of parallel phenotypic evolution through similar (parallel) vs different (convergent) genetic changes with particular focus on freshwater isolates. I will review and discuss the available genetic data with particular focus on freshwater fish populations, and outline possible avenues for future work in which ponds and small lakes could serve as useful model systems to study genetic parallelism and convergence, as well as molecular adaptation in general. Conservation issues related to genetics of isolated pond and lake populations are also addressed.
\end{abstract}

Key words: adaptation, convergent evolution, effective population size, genetic variability, fish, parallel evolution, quantitative trait.

Received: May 2013. Accepted: August 2013.

\section{INTRODUCTION}

Habitat structure and size can have major implications for the ecology and demography of populations, and thereby also to their genetic characteristics. Genetics, in turn, dictate how populations evolve, or fail to do so, in response to natural selection. Populations living in highly isolated habitats (whether natural or anthropogenically induced) can be subject to very different demographic, selective and genetic processes than those residing in continuous - or at least partially connected - habitats (Frankham et al., 2002). Lakes and ponds represent habitats which are often highly isolated and in many ways analogous to oceanic islands. Evolution on islands may differ in many ways from that on mainland (Barton, 1996). By analogy, evolution in ponds and lakes may differ in many ways from that in marine environments. For instance, assuming that effective population sizes in ponds and lakes are smaller than those in marine habitats, ponds and lakes may experience a lower incidence of advantageous mutations and accumulate larger drift load due to deleterious mutations (Kondrashov, 1995; Willi et al., 2013). Likewise, if ponds and lakes have been frequently founded by a small number of colonists, the impact of the initial bout of strong random drift on their genetic constitution, and thereby evolution, might have been large (Mayr, 1954; Templeton, 1980; Wright, 1982; Carson and Templeton, 1984). Last but not least, novel abiotic and biotic selective pressures - features not uncommon to populations colonizing islands (Losos and Ricklefs, 2009) or residing as habitat isolates (Levin, 1970; Lesica and Al- lendorf, 1995; Johansson et al., 2007; Willi et al., 2007) may have had a large impact on many pond and lake populations.

In general, island populations have lowered levels of genetic variability than mainland populations (Frankham, 1997). Similarly, comparative studies of population genetic variability and differentiation in marine $v s$ freshwater habitats in fishes have uncovered a large impact of habitat isolation on genetic characteristics of populations. A number of reviews (Gyllensten, 1985; Ward et al., 1994; DeWoody and Avise, 2000; Ward, 2004; McCusker and Benzen, 2010) and later case studies (DeFaveri et al., 2012) have provided evidence for lowered genetic variability and an increased degree of genetic differentiation among freshwater as compared to marine populations (Fig. 1). These results align with the interpretation that populations in finite and often very small freshwater habitats exhibit smaller effective population sizes than those living in marine habitats where populations are also connected by at least occasional gene flow. It is noteworthy that the polarized patterns of genetic variability and differentiation in freshwater $v s$ marine habitats cannot be explained by biased representation (e.g., differences in key life history traits influencing genetic variability) of species in each of these groupings; similar results are seen when populations of the same species residing in freshwater and marine habitats are compared (Mäkinen et al., 2006; Shikano et al., 2010; DeFaveri et al., 2012; Fig. 1). Hence, genetically speaking, populations of freshwater fishes are analogous to populations of terrestrial species on islands. 

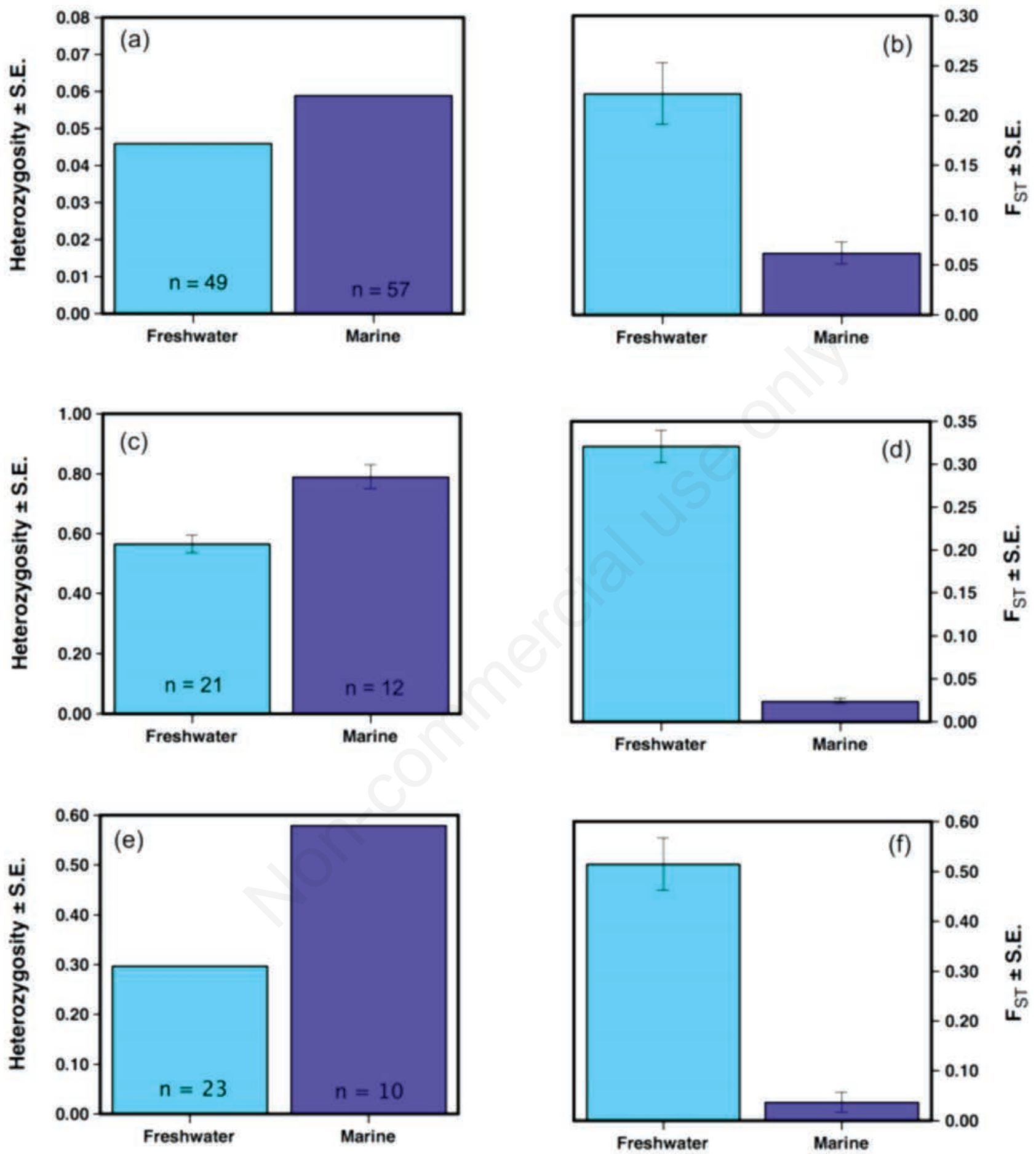

Habitat

Habitat

Fig. 1. Genetic variability differentiation in putatively neutral marker genes in freshwater and marine fishes. a) Average expected heterozygosity and b) average $\mathrm{F}_{\mathrm{ST}}\left( \pm \mathrm{S}\right.$.E) in allozyme loci in different fish species. c) Average expected heterozygosity and d) average $\mathrm{F}_{\mathrm{ST}}$ $\left( \pm\right.$ S.E) in 18 microsatellite loci in three-spined stickleback populations. e) Average expected heterozygosity and f) average $F_{S T}( \pm S . E)$ in 12 microsatellite loci in nine-spined stickleback populations. Data for a) and b) from Ward et al. (1994), for c) and d) from Mäkinen et al. (2006), and for e) and f) from Shikano et al. (2010); n, number of species/populations. 
Here, my aim is to explore the utility of small freshwater isolates (ponds and lakes) as model systems to study the genetic underpinnings of parallel phenotypic evolution. I will focus on the implications of small population size and a lack of (or restricted) gene flow on adaptation to novel and changing environmental conditions. In particular, I will explore the factors potentially influencing the likelihood of adaption to novel environmental conditions through similar (parallel) vs. different (convergent) genetic mechanisms, and whether these factors might differ between isolated (ponds and lakes) and open (rivers, marine habitats) populations. I will also briefly discuss the utility of small freshwater isolates as models for studies of molecular evolution and mutational loads. These should be consequential topics not only from the fundamental scientific point of view, but also from the applied perspective given the - often overlooked - importance of small freshwater isolates for ecosystem functioning and biodiversity (DeMeester et al., 2005; Downing, 2010).

\section{Utility of pond and lake populations to study of parallel evolution}

Isolated pond and lake populations provide ideal study systems to investigate parallel phenotypic evolution, defined as the independent evolution of similar phenotypic forms derived from a common ancestor, and its genetic underpinnings for a number of reasons. First, they represent independent replicates of evolution in the sense that they are not influenced by gene flow, at least in the case of true physical isolates. Second, given the importance of long-term effective population size $\left(N_{e}\right)$ as a determinant of the genetic characteristics of populations (see below), and the difficulties in actually measuring it (Luikart et al., 2010; Hare et al., 2011), it is convenient that heterozygosity provides a valid surrogate of $N_{e}$ in population isolates (Kimura and Crow, 1964; Crow and Kimura, 1970; Ohta and Kimura, 1973). Third, in the context of understanding the genetic underpinnings of phenotypic variability, population isolates may provide several analytical advantages over large outbred populations for gene-mapping (Peltonen et al., 2000; Karlsson and Lindblad-Toh, 2008). Fourth, as in the case of recently colonized postglacial or volcanic lakes, the evolutionary rates can often be assessed fairly accurately from geological information (Mobley et al., 2011).

Freshwater fishes have become important models for the study of parallel evolution. There are now numerous well-characterized examples of parallel evolution in diverse freshwater systems where fishes colonizing ecologically similar environments have evolved similar phenotypic characteristics (Tab. 1). This kind of repeated evolution of similar forms is difficult to reconcile except in the light of similar selection pressures driving evolution of similar forms: random processes such as genetic drift are not expected to result in independent evolution of similar forms in different localities (Schluter, 2000; Langer-

Tab. 1. Examples of parallel phenotypic evolution in freshwater fishes.

\begin{tabular}{|c|c|c|c|c|}
\hline Species & Habitat & Trait & Putative selection pressure & Reference \\
\hline \multirow{4}{*}{$\begin{array}{l}\text { Three-spined stickleback } \\
\text { (Gasterosteus aculeatus) }\end{array}$} & Post glacial lakes & Reduction in body armor & Reduced predation pressure & Colosimo et al., 2005 \\
\hline & & Body shape & & Albert et al., 2008 \\
\hline & & Coloration & Variation in predation risk & Miller et al., 2007 \\
\hline & & Suction & Foraging specialization & McGee and Wainwright, 2013 \\
\hline \multirow{4}{*}{$\begin{array}{l}\text { Nine-spined stickleback } \\
\text { (Pungitius pungitius) }\end{array}$} & Post glacial lakes & Large body size & Reduced predation pressure & Herczeg et al., 2009a \\
\hline & & Reduction in body armor & Reduced predation pressure & Herczeg et al., 2010 \\
\hline & & Lateral line traits & Reduced predation pressure & Trokovic et al., 2011 \\
\hline & & Behavioral traits & Reduced predation pressure & Herczeg et al., 2009b \\
\hline Whitefish (Coregonus sp.) & Post glacial lakes & Body size, etc. & Foraging specialization & Bernatchez et al., 2010 \\
\hline Mosquitofish (Gambusia hubbsi) & Bahama blueholes & Body shape & Variation in predation risk & Langerhans et al., 2007 \\
\hline Mosquitofish (Gambusia affinis) & Texas ponds & Body shape & Variation in predation risk & Langerhans and DeWitt, 2004 \\
\hline $\begin{array}{l}\text { Olomina } \\
\text { (Brachyraphis rhadophora) }\end{array}$ & Costra rica streams & Body shape & Variation in predation risk & Langerhans and DeWitt, 2004 \\
\hline \multirow[t]{3}{*}{$\overline{\text { Guppie (Poecilia reticulata) }}$} & Trinidad & Body shape & Piscine predation & Langerhans and DeWitt, 2004 \\
\hline & & Coloration & Variation in predation risk & Endler, 1980 \\
\hline & & Life history & Variation in predation risk & Reznick and Ghalambor, 2008 \\
\hline \multirow[t]{2}{*}{ Mexican cave tetra (Astyanax) } & & Coloration & Light regime & Protas et al., 2006; Gross et al., 2009 \\
\hline & & Eye loss & Light regime & Wilkens and Strecker, 2003 \\
\hline
\end{tabular}


hanz and DeWitt, 2004). In many instances, there is also genetic (Cresko et al., 2004; Colosimo et al., 2005; Chan et al., 2010; Østbye et al., 2008) and experimental (Endler, 1980, Reznick et al., 1997; Barrett et al., 2010) evidence to support the contention that the observed parallelism is caused by selection acting on heritable phenotypic variation.

\section{Genetics of parallel evolution}

The evolution of similar phenotypes can occur through parallel (similar) or convergent (different) genetic changes (Arendt and Reznick, 2008; Elmer and Meyer, 2011; Conte et al., 2012). In other words, populations can arrive at similar mean phenotypes by changes in the same or different genetic loci (or mutations). In a recent analysis of the probability of gene reuse in parallel and convergent phenotypic evolution, as inferred from data from a broad array of taxa, Conte et al. (2012) estimated mean probabilities of gene reuse ranging from 0.32 to 0.55 , depending on whether the data was derived from genetic crosses or candidate gene surveys, respectively. For parallel evolution, the mean probabilities of reuse of the same genes ranged from 0.42 (data from genetic crosses) to 0.67 (candidate gene data), whereas for convergent evolution the corresponding probabilities were 0.24 and 0.51 , respectively (Conte et al., 2012). They also found that the likelihood of gene reuse declined with time since divergence, suggesting that likelihood of genetic convergence increases with time (Conte et al., 2012). Despite the uncertainties associated with these estimates, they provide us with an exciting perspective which is conceptually similar to that provided by the concept of counter-gradient variation, referring to situations in which environmental influences generate phenotypic uniformity underlain by genetic differentiation (Conover and Schultz, 1995). In other words, both in the case of counter-gradient variation and genetic convergence, phenotypic similarities are underlain by genetic dissimilarities. The common occurrence of these distinct phenomena points to a shared generality: heterogeneous genetic architectures may frequently underlie phenotypic similarity.

\section{The importance of effective population size}

An evolutionary response to natural selection depends critically on the availability of genetic variation: the less variation, the less likely and the slower the evolutionary response will be (Falconer and McKay, 1996). In randomly mating populations, mutation and migration increase genetic variability, whereas drift and selection decrease it (Falconer and McKay, 1996). Single locus neutral models show that the amount of genetic variability in a population is an increasing function of effective population size $\left(N_{e}\right.$; reviewed in Willi et al., 2006). This is for two reasons. Firstly, the influence of genetic drift, leading to the loss of genetic variation, diminishes with increasing population size (Kimura, 1955). Secondly, fewer mutations appear in small than in large populations. However, given that the expected number of generations for the appearance of a new mutation at any given locus is $1 /\left(\mu N_{e}\right)$, where $\mu$ denotes the per locus mutation rate (Mueller, 1964), the impact of new mutations on genetic variability of recently established small populations, such as those living in post-glacially colonized ponds and lakes, is likely to have been low. Hence, the low levels of genetic variability in marker loci in post-glacially established pond and lake populations of fishes (see above; Fig. 1) suggests an important role for genetic drift in shaping their constitution. Likewise, the fact that new mutations are an unlikely source of novel genetic variation in small and young populations suggests an important role for standing genetic variation (Barrett and Schluter, 2008) in the evolutionary responses of these habitats.

\section{The importance of selection}

While migration tends to maintain genetic variation in populations, the influence of selection on genetic variability within populations is to reduce it. However, the effective population size matters here too: selection will be more efficient in large, than in small populations (Kimura, 1957; Robertson, 1960; Charlesworth, 2009). When population size decreases, the impact of genetic drift increases and loci under selection start to behave as neutral when selection coefficients (s) become equal or smaller than $1 /\left[2 N_{e}\right]$; Wright, 1931). Hence, to prevent the loss of rare beneficial alleles due to genetic drift, stronger selection is required in small than in larger populations.

In polygenic traits, reductions in genetic variability by selection are lessened by a large number of underlying loci (Crow and Kimura, 1970; Robertson, 1960). However, linkage disequilibrium created by selection on multilocus genotypes can reduce the number of independent loci due to the Bulmer effect (Bulmer, 1971), which can lead to a substantial reduction in levels of additive genetic variance $\left(\mathrm{V}_{\mathrm{A}}\right)$ (Verrier et al., 1991). Further drops in $\mathrm{V}_{\mathrm{A}}$ due to selection are likely to ensue because selection reduces $N_{e}$ by reducing the number of reproducing individuals, effectively increasing their relatedness and variance in reproductive success. All these fuel to increase the strength of drift and thereby also the erosion of genetic variation (Robertson and Hill, 1983; Verrier et al., 1991). Furthermore, the expected variance of $\mathrm{V}_{\mathrm{A}}$ increases with decreasing population size (and decreasing number of loci; Avery and Hill, 1977; Chakraborty and Nei, 1982), and hence, small populations are expected to exhibit large variance in their levels of genetic variability, both in $\mathrm{V}_{\mathrm{A}}$ and single locus heterozygosities (Frankham, 1996).

Given that genetic variability in small and recently es- 
tablished pond and lake populations is constrained by losses due to drift and lack of input from new mutations, the accidental loss of low frequency beneficial alleles might be an important factor influencing the likelihood of their usage in adaptation. This especially in the view that most traits of ecological importance are likely to be polygenic (Falconer and Mackay, 1996; Hill and Kirkpatrick, 2010; Yang et al., 2010), and thereby likely to be weakly selected at the level of individual loci (Turchin et al., 2012). Hence, it seems possible that the likelihood of parallel genetic differentiation in small populations could decrease with the increasing number of genes coding for a given trait.

\section{$\mathrm{N}_{\mathrm{e}}$ and selection - the importance of interaction}

The reduced efficiency of natural selection relative to genetic drift in small populations, also demonstrated in empirical studies (Jones et al., 1968; Weber and Diggins, 1990; Frankham and Weber, 2000; England et al., 2003; Willi et al., 2007; Johansson et al., 2007), illustrates how selection and $N_{e}$ can interact to influence evolutionary paths taken by populations. Using simple population genetic models supplemented with a literature review of 21 case studies, Cohan (1984a) highlighted the important point that identical selection regimes do not guarantee identical responses to selection: weak uniform (directional) selection combined with genetic drift results in a higher probability of fixation of alternative alleles than does pure drift over a wide range of initial allele frequencies (Cohan, 1984a; Fig. 2). In other words, the likelihood of two populations experiencing similar selection pressures fixing the same positively selected alleles declines with decreasing $N_{e}$. Hence, the likelihood of genetic parallelism is expected to be reduced in small populations. Conversely, large population sizes and strong selection are predicted to promote fixation of the same beneficial alleles in different populations derived from the same ancestral genetic pool.

Although Cohan's (1984a) conjecture has been supported by subsequent experimental work (Cohan, 1984b; Cohan and Hoffmann, 1989; Hoffmann and Cohan, 1987), it seems to have received relatively little attention in the scientific literature, despite the recent surge of interest in the study of parallel evolution (reviews in: Ardent and Reznick, 2008; Christin et al., 2010; Elmer and Meyer, 2011; Langerhans and Riesch, 2013). Nevertheless, the increasing number of examples of functional convergence (by definition caused by different genetic mechanisms) aligns with the notion that similar or equivalent phenotypic responses are often achieved via convergent genetic mechanisms (see below). To sum up, when it comes to quantitative traits of ecological importance, small populations are expected to respond to directional selection less readily than large populations on average, but for a given force and direction of
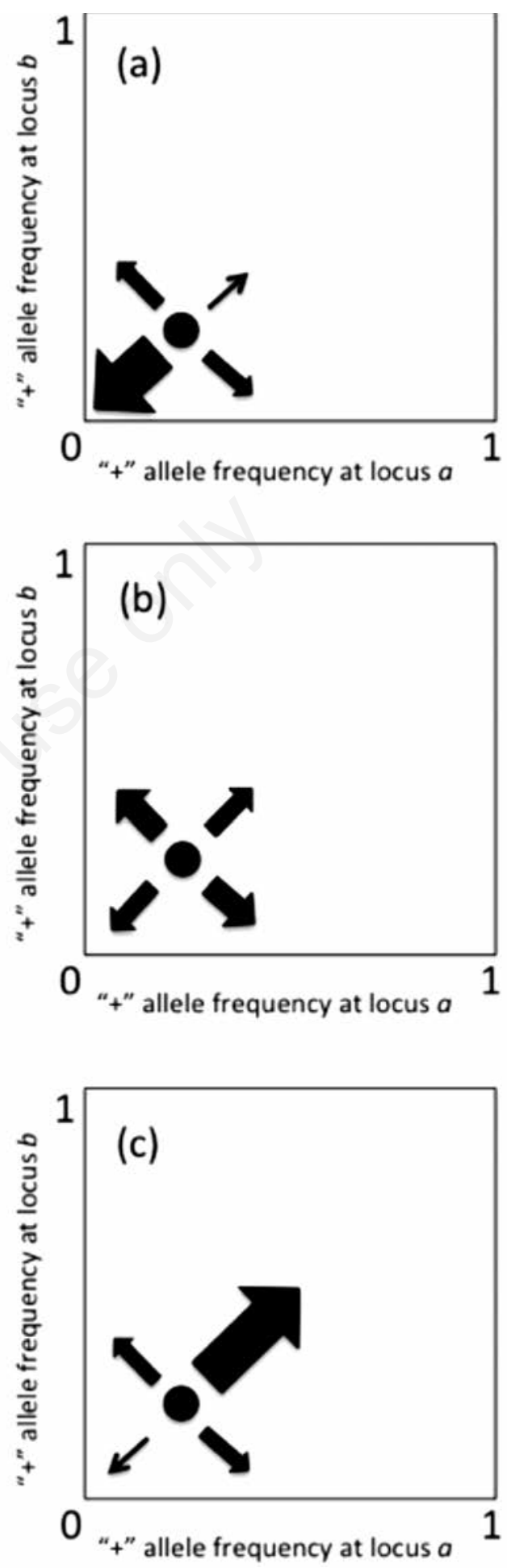

Fig. 2. Differentiation between two populations under a) genetic drift, b) weak selection and c) strong selection. In this two loci case, selection favors "+" alleles at both loci and population are drawn to $(1,1)$. Width of the arrows indicate the relative proportions of initially identical populations (represented by circle) evolving towards different directions. Note that the outcome in b) is less predictable than in a) and c). Re-drawn from Cohan (1984a). 
selection, these responses are expected to be more variable. One possible source of this variability may be the fixation and loss of alternative weakly selected alleles in different loci in small populations. By inference, parallel genetic responses could be more likely to occur in large, than in small populations, at least if the contribution of new mutations (and gene flow) for this divergence can be assumed to be small. Conversely, higher variance in the genetic constitution of small populations, such those residing in ponds and small lakes, might also facilitate the occurrence of convergent genetic responses in polygenic traits.

\section{Major vs minor genes}

In addition to the demographic and selective factors considered above, the likelihood of genetic parallelism may be influenced by various locus specific features (reviewed in: Christin et al., 2010), including the effect size of contributing loci/alleles. Although genetic changes of large effect are expected to contribute infrequently to adaptation (Fisher, 1930; Orr, 2005), potential disadvantages of largeeffect mutations are reduced when a population resides far from the optimal phenotype (Orr, 1998, 1999; Rogers et al., 2012 and references therein). In other words, large-effect alleles might still be expected to contribute in new or changing environmental conditions when selection is strong. Although one can only speculate about the relative strength of selection in pond and lake $v s$ marine environments, one thing seems logically clear: if genetic drift reduces the efficiency of natural selection in small pond and lake populations by rendering weakly selected, low frequency alleles effectively neutral, then one should perhaps expect a bias towards large effect alleles in adaptive transitions that have occurred in small freshwater isolates.

Coincidence or not, there are at least three well-characterized major genes (ectodysplasin: Colosimo et al., 2005; Pitx1: Shappiro et al., 2006; Kitlg: Miller et al., 2007) which have repeatedly contributed to adaptation to novel selection regimes in sticklebacks colonizing finite freshwater environments. Recently, Rogers et al. (2012) discovered that three-spined stickleback populations in lakes lacking predatory fishes showed a higher frequency of large effect QTL in body shape traits than those in lakes with predatory fishes. Under the reasonable assumption that the former represent selective environments more different from the ancestral marine conditions than the latter, these findings support the contention that the likelihood of adapting to strong novel selective pressures favors large effect loci/alleles.

\section{Functional convergence}

In addition to studies of parallel evolution, ponds and lakes have also started to attract interest in the context of convergent evolution, broadly defined as the occurrence of similar phenotypic forms which do not share recent ancestry, but have gone through a period of independent phenotypic and genetic evolution (Elmer and Meyer, 2011). Although the distinction between convergent $v s$ parallel evolution at the level of phenotype can be sometimes blurry (Ardent and Reznick, 2008; Pearce, 2012), convergent evolution defined in the manner above should not be confused with functional convergence.

Functional convergence refers to acquisition of similar functions through different phenotypic, and usually also genetic, pathways. It can also occur among populations sharing a common ancestor (Leinonen et al., 2012; McGee and Wainwright, 2013). Perhaps the clearest examples of functional convergence at the intraspecific level are provided by cases where populations have solved the same functional problem by evolving alternative phenotypes. Studies made in replicate pond and lake populations provide several examples of this. Studying lateral plate variation in threespined sticklebacks, Leinonen et al. (2012) discovered that three-spined sticklebacks in a few northern Fennoscandian ponds and small lakes had not gone through the typical reduction in lateral plate numbers which occurs when sticklebacks colonize freshwater habitats (Colosimo et al., 2005), but instead, reduced the height of their lateral plates rendering them effectively plateless. Genetic analyses suggested the possibility that reduction in plate size might have been an alternative pathway (sensu Bock, 1959) to reduce plate coverage in a situation where these populations were constrained by the lack of genetic variability (low plate Ectodysplasin alleles) to lose their plates (Leinonen et al., 2012). Although the tests for functional equivalence of low plated and small plated forms are still lacking, it seems possible that the two forms represent an example of functional convergence. In a more recent study, McGee and Wainwright (2013) discovered that while independent freshwater populations of three-spined sticklebacks had evolved stronger suction force as an adaptation to feed on benthic food, different populations used different morphological means to create the same enhanced suction force. These examples illustrate the point that even in cases where the populations are derived from the same ancestral stock, and subject to (apparent) uniform selection, the response to selection may occur not only by parallel or convergent genetic changes influencing the same target traits, but also by genetic changes in different aspects of their phenotype (see Garland et al., 2010; Huey et al., 2000; Endler et al., 2001; Calboli et al., 2003; Spitschak et al., 2007 for additional examples).

\section{Convergent genetic basis of parallel phenotypic evolution in ponds and lakes - empirical evidence}

Apart from the evidence for functional convergence wherein a heterogeneous genetic basis for phenotypic similarity is clear-cut, empirical evidence for the convergent 
genetic basis of parallel phenotypic evolution from freshwater fish populations is still scarce. However, studies of freshwater populations of three-spined sticklebacks utilizing genetic crosses have provided some evidence for the convergent genetic basis of parallel phenotypic evolution. In a study focused on three Alaskan lake populations of threespined sticklebacks, Cresko et al. (2004) found evidence for a parallel genetic basis for pelvis and armor reduction, presumably encoded by major gene effects in the Pitxl and EDA loci, respectively. However, careful analysis of results from complementation crosses suggested that different minor genes also had contributed to armor reduction, and these effects differed in different populations. In other words, evidence for a partly convergent genetic basis of differentiation was recovered. Similarly, in the analysis of EDA-locus driven armor reduction in three-spined sticklebacks, Colosimo et al. (2005) found that in one of the 15 populations studied, a convergent genetic basis underlies the loss of lateral plates (see also: Leinonen et al., 2012). Furthermore, as in the case of the three-spined stickleback, pelvic reduction in a Canadian nine-spined stickleback population appears to be controlled by a Pitxl enhancer (Shapiro et al., 2006). However, this seems not be to be case in all nine-spined stickleback populations: Stringham et al. (2000) have suggested that two other loci, unlinked to Pixt1, control pelvic reduction in two other populations of nine-spined sticklebacks (see also: Aldenhoven et al. 2010; Shapiro et al. 2009). Likewise, a recent QTL-analysis of genetic basis of pelvic reduction in a Fennoscandian nine-spined stickleback population has localized a large effect genetic factor responsible to pelvic reduction residing in a linkage group not containing Pitxl (Shikano et al., unpublished data).

Further evidence for a convergent genetic basis of parallel evolution comes from studies of eye loss in Mexican cave tetra (Astymax mexicanus). Crosses between fish from different cave populations restored the eyed phenotype only partially, suggesting that at some of the genes responsible for eye loss differ among populations (Wilkens, 1971; Wilkens and Strecker, 2003). Similarly, Protas et al. (2006) demonstrated that albinism in two Astymax populations had evolved independently through different mutations in the Oca2 locus, and provided evidence that a third independent mutation in the same locus (or its regulatory region) might explain albinism in a third population. Gross et al. (2009) discovered that reduced pigmentation in two independent Astymax populations had evolved through different mutations in the Mclr locus, providing further evidence for genetic converge towards similar phenotypes. Interestingly, the genetically isolated and independently evolved cave populations have strongly reduced genetic variability (Strecker et al., 2003), suggesting that genetic drift might have had a large impact on the course of their genetic differentiation.
Similar examples are available from many laboratory and terrestrial systems as well (reviewed in: Ardent and Reznick, 2008; Elmer and Meyer, 2011), and the relative paucity of evidence for convergent rather than parallel genetic basis of evidence from pond and lake systems might owe to the fact that most studies are designed detect parallel genetic changes, whereas convergent changes go more easily unrecognized. For instance, in pairwise comparisons of independent colonisations of freshwater environments, parallel genetic shifts in allele frequencies across population pairs give suggestive evidence for genetic parallelism, whereas non-parallel shifts are harder to interpret (DeFaveri et al., 2011). Likewise, the predominance of examples where major loci are underlying parallel genetic changes might be reflective of a bias caused by the ease at which genetic transformations in these loci can be detected. In this context, it is also worth pointing out that there is good evidence to suggest that the likelihood of parallel genetic evolution in the three-spined stickleback marine-freshwater systems might be profoundly affected by recurrent gene flow between marine and freshwater habitats (Schluter and Conte, 2009; Hohenlohe et al., 2012). This might predispose the marine three-spined sticklebacks to respond to selection in the freshwater environment through parallel rather than convergent genetic changes. The same might apply also to anadromous salmonid populations where straying can transport the same beneficial alleles from one river to another - a possibility exemplified by a recent study of Miller et al. (2011). This kind of possible bias should be of less concern in closed pond and lake populations, highlighting their utility for the study of genetic convergence.

\section{Evolution in small populations - the paradox}

In this context, it may be instructive to also consider the empirical evidence for evolutionary consequences of reduced effective sizes of pond and lake populations, and in particular, the fact that many pond and lake populations have apparently adapted to their respective habitats despite strongly reduced genetic variability. For instance, in spite of severely reduced genetic variability in isolated pond populations of nine-spined sticklebacks in Fennoscandia (Shikano et al., 2010), these populations show evidence for a high degree of parallel evolution in multiple phenotypic traits, apparently in response to lack of predation (reviewed in Merilä, 2013). Likewise, mosquitofish (Gambusia hubbsii) populations subject to strong genetic drift and low genetic variability (Shugg et al., 1998) show parallel adaptation in response predator mediated selection (Langerhans et al., 2007). In the same vein, Koskinen et al. (2002) discovered that introduced graylings (Thymallus thymallus) subject to a severe population bottleneck and associated loss of genetic variability due to (documented) low $N_{e}$ displayed evidence for 
strong local adaptation in multiple quantitative traits. More similar examples could be given, but these suffice to raise the point: if low $N_{e}$ compromises evolutionary potential of local populations, why are we still seeing widespread adaptions in small ponds and lakes?

Some resolution to this conundrum can be provided by the notion that the range of population sizes in which $N_{e}$ is expected to influence genetic variation in single locus and polygenic traits differs (Willi et al., 2006). In the case of marker genes, reductions can be expected at $N_{e}$ in the ball-park of a few thousand, whereas variability in quantitative traits starts to become influenced when population sizes go below a few hundred (Willi et al., 2006). Also, the length of the time (i.e. the number of generations) the populations remain at low size matters (Frankham et al., 2002). Hence, it may be that in the cases listed above, reductions in quantitative genetic variability have not been too severe to compromise the populations' adaptive potential. However, it is worth keeping in mind that what has happened in populations that went extinct usually goes unknown. Likewise, although the positive relationship between genetic variability in single locus genetic markers and $N_{e}$ is well established (Frankham, 1996; Willi et al., 2006; see above), empirical data on the relationship between additive genetic variance $\left(\mathrm{V}_{\mathrm{A}}\right)$ and $N_{e}$ is much more scarce. Nevertheless, the expected positive relationship has been found at least in some case studies (Swindell and Bouzat, 2005; Willi et al., 2007), and it seems to hold across studies as well, with some exceptions (Willi et al., 2006).

\section{Utility of population isolates to study molecular evolution}

Although the theoretical prediction that the rate and pattern of molecular evolution is influenced by effective population size $\left(N_{e}\right)$ is widely thought to apply, there are relatively few empirical studies directly testing this. In a comparative study of the effect of $N_{e}$ on molecular evolution, Woolfit and Bromham (2005) used independent island and mainland lineages to test for substitution rate differences under the assumption that the long-term $N_{e}$ of the latter are higher than that of the former. As predicted by theory, they found that island lineages had significantly higher ratios of non-synonymous to synonymous substitution rates than mainland lineages. However, overall substitution rates did not differ significantly (Woolfit and Bromham, 2005). This was explained by a low signal-tonoise ratio in the data, as this kind of difference has been earlier demonstrated for lineages with reduced $N_{e}$ (Kliman et al., 2000; Woolfit and Bromham, 2003). Similar studies comparing substitution rate differences could be easily performed in a number of pond and lake systems where the effective population sizes are either known, or can be safely inferred from estimates of heterozygosity under the assumption of population isolation (Kimura and Crow, 1964; Crow and Kimura, 1970; Ohta and Kimura, 1973).

\section{Conservation concerns and values}

Given the low genetic variability in many pond and lake populations as compared to populations of the same species residing in continuous marine environments, the fitness consequences of this lowered genetic variability, or its correlates, are also of both fundamental and applied interest. While the lowered genetic variability can influence the persistence of pond and lake populations directly through their ability to respond to novel or changing selection pressures, such as those imposed by climate change (Hoffmann and Willi, 2008), the genetic load imposed by small population sizes can also be of concern.

Segregation and drift loads measure the amount of fitness loss caused by segregation of recessive deleterious alleles due to inbreeding, and the load of deleterious alleles that have become fixed in the population due genetic drift, respectively (Lynch et al., 1995; Willi et al., 2013). In large populations both types of genetic loads are usually low: deleterious recessive alleles are sheltered by being in a heterozygous state, and genetic drift is unlikely to create drift load as it is a weak force in large populations (see above). However, in small populations the likelihood of deleterious alleles appearing in a homogenous state increases (=inbreeding), as does the drift load.

As to the empirical studies with respect to fitness consequences of low effective population size in fishes, salmonids may represent the best and most commonly studied model systems (Wang et al., 2002; Waples, 2004). Surprisingly, studies made on replicate populations of sticklebacks (popular models of ecological genetics research) in this context have been conspicuously scarce until lately (but see: Mazzi et al., 2002; Melhis et al., 2012). For instance, the genetically depauperate pond populations of nine-spined sticklebacks (Shikano et al., 2010; Trokovic et al., 2012) would provide good models to study variation in segregation and drift loads in isolated replicate populations not subject to confounding effects of gene flow. In fact, empirical studies to this effect are still rare in any organisms (van Treuren et al., 1993; Paland and Schmid, 2003; Willi et al., 2005; Escobar et al., 2008; Coutellec and Caquet, 2011; Willi et al., 2013). This in spite of the fact that the issue is important not least in the view that populations remaining small and isolated for extensive time periods, such as the post glacially isolated pond populations of nine-spined sticklebacks in Fennoscandia (Merilä, 2013), are likely to accumulate substantial drift load with negative effects on mean population fitness. If so, their ability to adapt to environmental changes such as climate warming may be seriously constrained not only by low levels of genetic variability, but also by drift load (Hoffmann and Willi, 2008). 
Finally, the fact that peripheral populations (including many pond and lake populations of various species) are often genetically and phenotypically distinct from central (and marine) populations gives them special value in a conservation context (Frankham et al., 2002; Gebremedhin et al., 2009). In fact, for their size and frequency, their conservation value may be disproportionally large as compared to large and more central populations (Lesica and Allendorf, 1995). If the perspectives put forth in this paper turn out to be generally correct, this may be even an understatement: if heterogeneous genetic differentiation underlying phenotypic similarity (i.e. genetic convergence), as well as the occurrence of functional convergence (by definition based on genetic divergence) are common, a lot of what has previously been perceived as homogeneity is in fact diversity.

\section{CONCLUSIONS}

Taken together, a rich body of ecological theory, starting from MacArthur and Wilson (1967), has provided important insights towards the determinants of biotic ecological characteristics of habitat isolates (reviewed in: Losos and Ricklefs, 2009). Similarly, early research on speciation had a strong emphasis on population isolates (Mayr, 1954; Carlson and Templeton, 1984; Barton and Charlesworth, 1984): a theme which has attained renewed interest as ecology's role in the speciation process has come into focus (Schluter, 1996, 2000; Langerhanz et al., 2007; Nosil, 2012). Habitat isolates with reduced population sizes have also been the focus of a considerable amount of theoretical and empirical work in the context of conservation biology and genetics (reviewed in: Saunders et al., 1991; Frankham et al., 2002; Allendorf and Luikart, 2007). All these vigorous fields of research focused on habitat isolates highlight the utility of ponds and lakes as model systems in contemporary evolutionary biology.

In this perspective, studies focused on isolated pond and lake populations are likely to continue to provide interesting opportunities to further advance our understanding of the process and genetic underpinnings of adaptation. Studies of genetically and demographically independent replicate populations derived from the same common ancestors (such as many post-glacially established freshwater populations of temperate zone fishes) have provided numerous examples of this (Taylor, 1999; Schluter, 2000; Rogers et al., 2013). Here, my argument has been that these study systems may yield even more. In particular, the many-fold consequences of reduced effective population size of pond and small lake populations on their genetic constitution might predispose them to respond to uniform selection differently. In other words, the loss and random fixation of (even beneficial) alleles due to founder effects and genetic drift might promote evolution of heterogeneous genetic architecture underlying phe- notypic adaptation to similar selection pressures in replicate populations. Therefore, evolution of parallel phenotypic differentiation in response to similar selection pressures through convergent genetic changes might be more likely in small (more divergent genetic architecture) than in large (more similar genetic architecture) populations. Similarly, by providing independent replicates of evolution, isolated pond and lake populations are likely to provide us with useful model systems to study and test ideas in the realms of molecular evolution and conservation genetics.

\section{ACKNOWLEDGMENTS}

I thank Jacquelin DeFaveri and Scott McCairns useful discussions and comments which improved earlier versions of this manuscript, and in particular, Angela Boggero, Diego Fontaneto, Giuseppe Morabito and Pietro Volta for kind invitation to write this perspective. During the writing of this manuscript, I have benefitted from the support by the Academy of Finland (grants \#250435 and \#265211).

\section{REFERENCES}

Albert AY, Sawaya S, Vines TH, Knecht AK, Miller CT, Summers BR, Balabhadra S, Kingsley DM, Schluter D, 2008. The genetics of adaptive shape shift in stickleback: Pleiotropy and effect size. Evolution 62:76-85.

Aldenhoven JT, Miller MA, Showers Corneli P, Shapiro MD, 2010. Phylogeography of ninespine sticklebacks (Pungitius pungitius) in North America: glacial refugia and the origins of adaptive traits. Mol. Ecol. 19:4061-4076.

Allendorf F, Luikart G, 2007. Conservation and the genetics of populations. Blackwell, Oxford: $624 \mathrm{pp}$.

Arendt J, Reznick D, 2008. Convergence and parallelism reconsidered: what have we learned about the genetics of adaptation? Trends Ecol. Evol. 23:26-32.

Avery PJ, Hill WG, 1977. Variability in genetic parameters among small populations. Genet. Res. 29:193-213.

Barrett RDH, Schluter D, 2008. Adaptation from standing genetic variation. Trends Ecol. Evol. 23:38-44.

Barrett RDH, Paccard A, Healy TM, Bergek S, Schulte PM, Schluter S, Rogers SM, 2010. Rapid evolution of cold tolerance in stickleback. P. R. Soc. B 278:233-238.

Barton NH, 1996. Natural selection and random genetic drift as causes of evolution on islands. Phil. T. Roy Soc. B 351:785-794.

Barton NH, Charlesworth B, 1984. Genetic revolutions, founder events and speciation. Annu. Rev. Ecol. Syst. 15:133-164.

Bock WJ, 1959. Preadaptation and multiple evolutionary pathways. Evolution 13:194-211.

Bulmer MG, 1971. Effect of selection on genetic variability. Am. Nat. 105:201-211.

Bernatchez L, Renaut S, Whiteley A, Derome N, Jeukens J, Landry L, Lu G, Nolte AW, Østbye KJ, Rogers SM, St-Cyr J, 2010. On the origins of species: Insights from the ecological genomics of whitefish. Phil. T. Roy Soc. B 365:1783-1800.

Calboli FCF, Gilchrist GW, Partridge L, 2003. Different cell size 
and cell number contribution in two newly established and one ancient body size cline of Drosophila subobscura. Evolution 57:566-573.

Carson HL, Templeton AR, 1984. Genetic revolutions in relation to speciation phenomena: the founding of new populations. Annu. Rev. Ecol. Syst. 15:97-113.

Chakraborty R, Nei M, 1982. Genetic differentiation of quantitative characters between populations or species. I. Mutation and random genetic drift. Genet. Res. 39:303-314.

Chan YF, Marks ME, Jones FC, Villarreal G Jr., Shapiro MD, Brady SD, Southwick AM, Absher DM, Grimwood J, Schmutz J, Myers RM, Petrov D, Jónsson B, Schluter D, Bell MA, Kingsley DM, 2010. Adaptive evolution of pelvic reduction in sticklebacks by recurrent deletion of a Pitx 1 enhancer. Science 5963:302-305.

Charlesworth B, 2009. Effective population size and patterns of molecular evolution and variation. Nat. Rev. Gen. 10:195-205.

Christin PA, Weinrich DM, Besnard G, 2010. Causes and evolutionary significance of genetic convergence. Trends Genet. 26:400-405.

Cohan FM, 1984a. Can uniform selection retard random genetic divergence between isolated conspecific populations? Evolution 38:495-504.

Cohan FM, 1984b. Genetic divergence under uniform selection. I. Similarity among populations of Drosophila melanogaster in their responses to artificial selection for modifiers of ciD. Evolution 38:55-71.

Cohan FM, Hoffmann AA, 1989. Uniform selection as a diversifying force in evolution: evidence from Drosophila. Am. Nat. 134:613-637.

Colosimo PF, Hosemann KE, Balabhadra S, Villarreal G Jr., Dickson M, Grimwood J, Schmutz J, Myers RM, Schluter D, Kingsley DM, 2005. Widespread parallel evolution in sticklebacks by repeated fixation of ectodysplasin alleles. Science 307:1928-1933.

Conover DO, Schultz ET, 1995. Phenotypic similarity and the evolutionary significance of countergradient variation. Trends Ecol. Evol. 10:248-252.

Conte GL, Arnegard ME, Peichel CL, Schluter D, 2012. The probability of genetic parallelism and convergence in natural populations. P. R. Soc. B 279:5039-5047.

Coutellec MA, Caquet T, 2011. Heterosis and inbreeding depression in bottlenecked populations: a test in the hermaphroditic freshwater snail Lymnaea stagnalis. J. Evol. Biol. 24:2248-2257.

Cresko WA, Amores A, Wilson C, Murphy J, Currey M, Phillips P, Bell MA, Kimmel CB, Postlethwait JH, 2004. Parallel genetic basis for repeated evolution of armor loss in Alaskan threespine stickleback populations. Proc. Natl. Acad. Sci. U. S. A. 101: 6050-6055.

Crow JF, Kimura M, 1970. An Introduction to Population Genetics Theory. Burgess: Minneapolis, MN, USA.

DeFaveri J, Shikano T, Shimada Y, Goto A, Merilä J, 2011. Global analysis of genes involved in freshwater adaptation in threespine sticklebacks (Gasterosteus aculeatus). Evolution 65:1800-1807.

DeFaveri, J, Shikano T, Ab Ghani NI, Merilä J, 2012. Contrasting population structures in two sympatric fishes in the Baltic Sea basin. Mar. Biol. 159:1659-1672.
DeMeester L, Delerck S, Stoks R, Louette G, Van de Meutter F, de Bie T, Michels E, Brendonk L, 2005. Ponds and pools as model systems in conservation biology, ecology and evolutionary biology. Aquat. Conserv. 15:715-725.

DeWoody JA, Avise JC, 2000. Microsatellite variation in marine, freshwater and anadromous fishes compared with other animals. J. Fish Biol. 56:461-473.

Downing JA, 2010. Emerging global role of small lakes and ponds: little things mean a lot. Limnetica 29:9-24.

Elmer KR, Meyer A, 2011. Adaptation in the age of ecological genomics: insights from parallelism and convergence. Trends Ecol. Evol. 26:298-306.

Endler, JA 1980. Natural selection on color patterns in Poecilia reticulata. Evolution 34:76-91.

Endler JA, Basolo A, Glowacki S, Zerr J, 2001. Variation in response to artificial selection for light sensitivity in guppies (Poecilia reticulata). Am. Nat. 158:36-48.

England PR, Osler GHR, Woodworth LM, Montgomery ME, Briscoe DA, Frankham R, 2003. Effects of intense versus diffuse population bottlenecks on microsatellite genetic diversity and evolutionary potential. Conserv. Genet. 4:595-604.

Escobar JS, Nicot A, David P, 2008. The different sources of variation in inbreeding depression, heterosis and outbreeding depression in a metapopulation of Physa acuta. Genetics 180:1593-1608.

Falconer DS, Mackay TFC, 1996. Introduction to quantitative genetics, 4th ed., B. Longman: $480 \mathrm{pp}$.

Fisher RA, 1930. The genetical theory of natural selection. Oxford University Press, Oxford: 265 pp.

Frankham R, 1996. Relationship of genetic variability to population size in wildlife. Conserv. Biol. 10:1500-1508.

Frankham R, 1997. Do island populations have less genetic variation than mainland populations? Heredity 78:311-327.

Frankham R, Ballou JD, Briscoe DA, 2002. Introduction to conservation genetics. Cambridge University Press: 644 pp.

Frankham R, Weber KE, 2000. Nature of quantitative genetic variation, p. 351-368. In: R.R. Singh and C.B. Crimbas (eds.), Evolutionary genetics: from molecules to morphology. Cambridge University Press.

Garland T Jr., Kelly SA, Malisch JL, Kolb EM, Hannon RM, Keeney BK, Van Cleave SL, Middleton KM, 2010. How to run far: multiple solutions and sex-specific responses to selective breeding for high voluntary activity levels. P. R. Soc. B 278:574-581.

Gebremedhin B, Ficetola GF, Naderi S, Rezaei H-R, Maudet C, Rioux D, Luikart G, Flagstad Ø, Thuiller W, Taberlet P, 2009. Frontiers in identifying conservation units: from neutral markers to adaptive genetic variation. Anim. Cons. 12:107-109.

Gross JB, Borowsky R, Tabin CJ, 2009 A novel role for Mc1r in the parallel evolution of depigmentation in independent populations of the cavefish Astyanax mexicanus. PLoS Genet. 5:e1000326.

Gyllensten U, 1985. The genetic structure of fish - differences in the intraspecific distribution of biochemical genetic variation between marine anadromous, and fresh-water species. J. Fish Biol. 26:691-699.

Hare MP, Nunney L, Schwartz MK, Ruzzante DE, Burford M, Waples RS, Ruegg K, Palstra F, 2011. Understanding and estimating effective population size for application in marine species management. Conserv. Biol. 25:439-449. 
Herczeg G, Gonda A, Merilä J, 2009a. Evolution of gigantism in ninespine sticklebacks. Evolution 63:3190-3200.

Herczeg G, Gonda A, Merilä J, 2009b. Predation mediated population divergence in complex behaviour of ninespine stickleback (Pungitius pungitius). J. Evol. Biol. 22:544-552.

Herczeg G, Turtiainen M, Merilä J, 2010. Morphological divergence of North-European nine-spined sticklebacks (Pungitius pungitius): signatures of parallel evolution. Biol. J. Linn. Soc. 101:403-416.

Hill WG, Kirkpatrick M, 2011. What animal breeding has taught us about evolution? Annu. Rev. Ecol. Syst. 41:1-19.

Hoffmann AA, Cohan FM, 1987. Genetic divergenxe under uniform selection. III. Selection for knockdown resistance to ethanol in Drosophila pseudoobscura populations and their replicate lines. Heredity 58:425-433.

Hoffmann AA, Willi Y, 2008. Detecting genetic responses to environmental change. Nat. Rev. Genet 9:421-432.

Hohenlohe PA, Bassham S, Currey M, Cresko WA, 2012. Extensive linkage disequilibrium and parallel adaptive divergence across threespine stickleback genomes. Phil. T. Roy Soc. B 367:395-408.

Huey RB, Gilchrist GW, Carlson ML, Berrigan D, Serra L, 2000. Rapid evolution of a geographic cline in size in an introduced fly. Science 287:308-309.

Johansson M, Primmer CR, Merilä J, 2007. Does habitat fragmentation reduce fitness and adaptability? A case study of the common frog (Rana temporaria). Mol. Ecol. 16:2693-2700.

Jones LP, Frankham R, Barker JSF, 1968. The effects of population size and selection intensity in selection for a quantitative character in Drosophila II. Long-term response. Genet. Res. 12:249-266.

Karlsson EK, Lindblad-Toh K, 2008. Leader of the pack: gene mapping in dogs and other model organisms. Nat. Rev. Gen. 9:713-725.

Kimura M, 1955. Solution of a process of random genetic drift with a continuous model. P. Natl. Acad. Sci. USA 41:144-150.

Kimura M, 1957. Some problems of stochastic processes in genetics. Ann. Math. Stat. 28:882-901.

Kimura M, Crow JF, 1964. The number of alleles that can be maintained in a finite population. Genetics 49:725-738.

Kliman RM, Andolfatto P, Coyne JA, Depaulis F, Kreitman M, Berry AJ, McCarter J, Wakeley J, Hey J, 2000. The population genetics of the origin and divergence of the Drosophila simulans complex species. Genetics 156:1913-1931.

Kondrashov AS, 1995. Contamination of the genome by very slightly deleterious mutations - why have we not died 100 time over. J. Theor. Biol. 175:583-594.

Koskinen MT, Haugen TO, Primmer CR, 2002. Contemporary fisherian life-history evolution in small salmonid populations. Nature 419: 826-830.

Langerhans RB, DeWitt TJ, 2004. Shared and unique features of evolutionary diversification. Am. Nat. 164:335-349.

Langerhans RB, Gifford ME, Everton OJ, 2007. Ecological speciation in Gambusia fishes. Evolution 61:2056-2074.

Langerhans RB, Riesch R, 2013. Speciation by selection: a framework for understanding ecology's role in speciation. Curr. Zool. 59:31-52.

Leinonen T, McCairns RJS, Herczeg G, Merilä J, 2012. Multiple evolutionary pathways to decreased plate coverage in freshwater threespine stickleback. Evolution 66:38663875 .
Lesica P, Allendorf FW, 1995. When are peripheral populations valuable for conservation? Conserv. Biol 9:755-760.

Levin DA, 1970. Developmental instability and evolution in peripheral populations. Am. Nat. 104:343-353.

Losos JB, Ricklefs RE, 2009. Adaptation and diversification on islands. Nature 457:830-836.

Luikart G, Ryman N, Tallmon DA, Schwartz, Allendorf FW, 2010. Estimation of census and effective population sizes: the increasing usefulness of DNA-based approaches. Conserv. Genet. 11:355-373.

Lynch M, Conery J, Bürger R, 1995. Mutation accumulation and the extinction of small populations. Am. Nat. 146:489-518.

MacArthur RH, Wilson EO, 1967. The theory of island biogeography. Princeton University Press: 203 pp.

Mayr E, 1954. Change of genetic environment and evolution, $\mathrm{p}$. 157-180. In: J. Huxley and E.B. Ford (eds.), Evolution as a process. Allen \& Unwin, London.

Mazzi D, Largiader CR, Bakker TCM, 2002. Inbreeding and developmental stability in three-spined sticklebacks (Gasterosteus aculeatus L.). Heredity 89:293-299.

McCusker MR, Bentzen P, 2010. Positive relationships between genetic diversity and abundance in fishes. Mol. Ecol. 19:4852-4862.

McGee MD, Wainwright PC, 2013. Convergent evolution as a generator of phenotypic diversity in threespine stickleback. Evolution 67:1204-1208.

Melhis M, Frommen JG, Rahn AK, Bakker TCM, 2012. Inbreeding in three-spined sticklebacks (Gasterosteus aculeatus L.): effects on testis and sperm traits. Biol. J. Linn. Soc. 107:510-520.

Merilä J, 2013. Nine-spined stickleback (Pungitius pungitius): an emerging model for evolutionary biology research. Ann. N. Y. Acad. Sci. 1289:18-35.

Miller CT, Beleza S, Pollen AA, Schluter D, Kittles RA, Shiver MD, Kingsley DM, 2007. cis-Regulatory changes in Kit Ligand expression and parallel evolution of pigmentation in sticklebacks and humans. Curr. Biol. 131:11791189.

Miller M, Brunelli JP, Wheeler PA, Liu S, Redroad CE, Palti Y, Doe CQ, Thorgaard GH, 2011. A conserved haplotype controls parallel adaptation in geographically distant salmonid populations. Mol. Ecol. 21:237-249.

Mobley KB, Lussetti D, Johansson F, Englund G, Bokma F, 2011. Morphological and genetic divergence in Swedish postglacial stickleback (Pungitius pungitius) populations. BMC Evol. Biol. 11:287.

Mueller HJ, 1964. The relation of recombination to mutational advance. Mutat. Res. 1:2-9.

Mäkinen HS, Cano JM, Merilä J, 2006. Genetic relationships among marine and freshwater populations of the European three-spined stickleback (Gasterosteus aculeatus) revealed by microsatellites. Mol. Ecol. 15:1519-1534.

Nosil P, 2012. Ecological speciation. Oxford University Press, Oxford: 304 pp.

Ohta T, Kimura M, 1973. A model of mutation appropriate to estimate the number of electrophoretically detectable alleles in a finite population. Genet. Res. 22:201-204.

Orr HA, 1998. Population genetics of adaptation: the distribution of factors fixed during adaptive evolution. Evolution 52:935-949. 
Orr HA, 1999. The evolutionary genetics of adaptation: a simulation study. Genet. Res. 74:207-214.

Orr HA, 2005. The probability of parallel evolution. Evolution 59:216-220.

Paland S, Schmid B, 2003. Population size and the nature of genetic load in Gentianella germanica. Evolution 57: 22422251 .

Pearce T, 2012. Convergence and parallelism in evolution: a Neo-Gouldian account. Brit. J. Philos. Sci. 63:429-448.

Peltonen L, Palotie A, Lange K, 2000. Use of population isolates for mapping complex traits. Nat. Rev. Genet. 1:182190.

Protas ME, Hersey C, Kochanek D, Zhou Y, Wilkens H, Jeffery WR, Zon LI, Borowsky R, Tabin CJ, 2006. Genetic analysis of cavefish reveals molecular convergence in the evolution of albinism. Nat. Genet. 38:107-111.

Reznick DN, Ghambor CK, 2008. Can commercial fishing cause evolution? Answers from guppies (Poecilia reticulata). Can. J. Fish. Aquat. Sci. 62:791-801.

Reznick DN, Shaw FH, Rodd H, Shaw RG, 1997. Evaluation of the rate of evolution in natural populations of guppies (Poecilia reticulate). Science 275:1943-1937.

Rogers SM, Tamkee P, Summers B, Balabahadra S, Marks M, Kingsley DM, Schluter D, 2012. Genetic signature of adaptive peak shift in threespine stickleback. Evolution 60:2439-2450.

Rogers SM, Mee JA, Bowles E, 2013. The consequences of genomic architecture on ecological speciation in postglacial fishes. Curr. Zool. 59:53-71.

Robertson A, 1960. A theory of limits in artificial selection. P. R. Soc. B. 153:234-249.

Robertson A, Hill WG, 1983. Population and quantitative genetics of many linked loci in finite populations. P. R. Soc. B 219:253-264.

Saunders DH, Hobbs RJ, Margules CR, 1991. Biological consequences of ecosystem fragmentation: a review. ConsERV. Biol. 5:18-32.

Schluter D, 1996. Ecological speciation in postglacial fishes. Phil. T. Roy Soc. B 351:807-814.

Schluter D, 2000. The ecology of adaptive radiation. Oxford University Press: 296 pp.

Schluter D, Conte G, 2009. Genetics and ecological speciation. P. Natl. Acad. Sci. USA 106:9955-9962.

Shapiro MD, Bell MA, Kingsley DM, 2006. Parallel genetic origins of pelvic reduction in vertebrates. P. Natl. Acad. Sci. USA 103:13753-13758.

Shapiro MD, Summers BR, Balabhadra S, Aldenhoven JT, Miller AL, Cunningham CB, Bell MA, Kingsley DM, 2009. The genetic architecture of skeletal convergence and sex determination in ninespine sticklebacks. Curr. Biol. 19:1140-1145.

Shikano T, Shimada Y, Herczeg G, Merilä J, 2010. History vs. habitat type: explaining the genetic structure of European nine-spined stickleback (Pungitius pungitius) populations. Mol. Ecol. 19:1147-1161.

Shugg MD, Downhower JF, Brown LP, Sears DB, Fuerst PA, 1998. Isolation and genetic diversity of Gambusia hubbsi (mosquitofish) populations in blueholes on Andros Island, Bahamas Heredity 80:336-346.

Spitschak M, Langhammer M, Schneider F, Renne U, Vanselow J, 2007. Two high-fertility mouse lines show differences in component fertility traits after long-term selection. Reprod. Fertil. Dev. 19:815-821.

Strecker U, Bernatchez L, Wilkens H, 2003. Genetic divergence between cave and surface populations of Astyanax in Mexico (Characidae, Teleostei). Mol. Ecol. 12:699-710.

Stringham SA, Aldenhoven JT, Tampio AJ, Miller AL, Lunsford AR, Shapiro MD, 2011. Diverse genetic mechanisms underlie pelvic reduction in ninespine sticklebacks (Pungitius pungitius). Integr. Comp. Biol. 51:E134.

Swindell WR, Bouzat JL, 2005. Modeling the adaptive potential of isolated populations: experimental simulations using Drosophila. Evolution 59:2159-2169.

Taylor EB, 1999. Species pairs of north temperate freshwater fishes: evolution, taxonomy, and conservation. Rev. Fish Biol. Fisher. 9:299-324.

Templeton AR, 1980. The theory of speciation via the founder principle. Genetics 94:1011-1038.

Turchin MC, Chiang CWK, Palmer CD, Sankararaman S, Reich D, Genetic Investigation of ANthropometric Traits (GIANT) Consortium, Hirschhorn JN, 2012. Evidence of widespread selection on standing variation in Europe at height-associated SNPs. Nat. Genet. 44:1015-1019.

Trokovic N, Herczeg G, Ab-Ghani NI, Shikano T, Merilä J, 2012. High levels of fluctuating asymmetry in isolated stickleback populations. BMC Evol. Biol. 12:115.

Trokovic N, Herczeg G, McCairns RJS, Ab Ghani NI, Merilä J, 2011. Intraspecific divergence in the lateral line system in the nine-spined stickleback (Pungitius pungitius). J. Evol. Biol. 24:1546-1558.

Yang J, Benyamin B, McEvoy BP, Gordon S, Henders AK, Nyholt DR, Madden PA, Heath AC, Martin NG, Montgomery GW, Goddard ME, Visscher PM, 2010. Common SNPs explain a large proportion of the heritability for human height. Nat. Genet. 42:565-569.

van Treuren R, Bijlsma R, Ouborg NJ, van Delden W, 1993. The significance of genetic erosion in the process of extinction. IV. Inbreeding depression and heterosis effects caused by selfing and outcrossing in Scabiosa columbaria. Evolution 47:1669-1680.

Verrier E, Colleau JJ, Foulley JL, 1991. Methods for predicting response to selection in small populations under additive genetic models: a review. Livest. Prod. Sci. 29:93-114.

Østbye K, Amundsen P-A, Bernatchez L, Klemetsen A, Knudsen A, Kristoffersen R, NÆsje TF, Hindar K, 2008. Parallel evolution of ecomorphological traits in the European whitefish Coregonus lavaretus (L.) species complex during postglacial times. Mol. Ecol. 15:3983-4001.

Wang S, Hard JJ, Utter F, 2002. Salmonid inbreeding: a review. Rev. Fish Biol. Fisher. 11:301-319.

Waples RS, 2004. Salmonid insights into effective population size, p. 295-314. In: A.P. Hendry and S.C. Stearns (eds.), Evolution illuminated: salmon and their relatives. Oxford University Press.

Ward RD, 2004. Genetics of fish populations, p. 200-224. In: P.J.B. Hart and J.D. Reynolds (eds.), Handbook of Fish Biology and Fisheries, vol 1. Blackwell Publishing Ltd., Oxford.

Ward RD, Woodwark M, Skibinski DOF, 1994. A comparison of genetic diversity levels in marine, freshwater, and anadromous fishes. J. Fish Biol. 44:213-232. 
Weber KE, Diggins LT, 1990. Increased selection response in larger populations. II. Selection for ethanol vapor resistance in Drosophila melanogaster. Genetics 125:585-597.

Wilkens H, 1971. Genetic interpretation of regressive evolutionary processes: studies on hybrid eyes of two Astyanax cave populations. Evolution 25:530-544.

Wilkens H, Strecker U, 2003. Convergent evolution of the cavefish Astyanax (Characidae, Teleostei): genetic evidence from reduced eye-size and pigmentation. Biol J. Linn. Soc. 80:545-554.

Willi Y, Griffin P, Van Buskirk J, 2013. Drift load in populations of small size and density. Heredity 110:296-302.

Willi Y, Van Buskirk J, Fischer M, 2005. A threefold genetic Allee effect: population size affects cross-compatibility, inbreeding depression and drift load in the self-incompatible Ranunculus reptans. Genetics 169:2255-2265.
Willi Y, Van Buskirk J, Hoffmann AA, 2006. Limits to the adaptive potential of small populations. Annu. Rev. Ecol. Syst. 17:433-458.

Willi Y, Van Buskirk J, Schmid B, Fischer M, 2007. Genetic isolation of fragmented populations is exacerbated by drift and selection. J. Evol Biol. 20:534-542.

Woolfit M, Bromham L, 2003. Increased rates of sequence evolution in endosymbiotic bacteria and fungi with small effective population sizes. Mol. Biol. Evol. 20:15451555.

Woolfit M, Bromham L, 2005. Population size and molecular evolution on islands. P. R. Soc. B. 272:2277-2282.

Wright S, 1931. Evolution in Mendelian populations. Genetics 16:97-159.

Wright S, 1982. The shifting balance theory and macroevolution. Annu. Rev. Genet. 16:1-19. 